Araştırma Makalesi - Research Article

\title{
Roof-KSA: Binaların Semantik Bölütlemesi İçin Az Parametreye Sahip Konvolüsyonel Sinir Ağı Modeli
}

Geliş / Received: 23/05/2020

Umut Özkaya ${ }^{1 *}$, Şaban Öztürk ${ }^{2}$

Revize / Revised: 24/09/2020

Kabul / Accepted: 05/10/2020

ÖZ

Günümüzde güneş enerjisi, enerji alt yapısının sağlanmasında vazgeçilmez bir unsur haline gelmiştir. Yerleşim yerlerinde bulunan bina çatılarının güneş enerjisi potansiyelinin tahmin edilebilmesi bu enerjinin etkin kullanılabilmesi için önemlidir. Günümüzde yapay zeka algoritmalarındaki gelişmeler sayesinde bu gibi işler bilgisayarlar tarafından otomatik olarak gerçekleştirilmektedir. Bu çalışmada ise yapay zeka algoritmalarının en gelişmişi olan derin öğrenme mimarilerinden faydalanarak bir çözüm önerilmektedir. Bu çalışmada bina çatılarının semantik bölütlenmesi için az parametreye sahip Roof-KSA adı verilen Konvolüsyonel Sinir Ağı modeli önerilmiştir. Semantik bölütleme işlemi için toplamda 3400 adet $224 \times 224 \times 3$ piksel boyutlarında uydu görüntülerinden yararlanılmıştır. Roof-KSA modeli toplam 10 katmana ve 104,450 adet güncellenebilen parametreye sahiptir. Karşılaştırmalı analiz kapsamında Roof-KSA modeli kullanılan U-Net modellerine göre oldukça az parametreye sahiptir. Ayrıca Roof-KSA modeli 0.91404 küresel doğruluk oranı, 0.73092 ortalama doğruluk oranı, 0.65537 ortalama eşleşmiş bölge oranı, 0.84918 ağırlıklandırılmış eşleşmiş bölge oranı ve 0.67244 ortalama BF skoru ile ön plana çıkmaktadır. Elde edilen semantik bölütleme sonuçları dikkate alındığında RoofKSA modelinin oldukça başarılı olduğu görülmektedir.

Anahtar Kelimeler- Güneş Enerjisi, Derin Ö̆̆grenme, Semantik Bölütleme, Konvolüsyonel Sinir Ağları

\footnotetext{
1*Sorumlu yazar iletișim: uozkaya@ktun.edu.tr (https://orcid.org/0000-0002-9244-0024)

Elektrik Elektronik Mühendisliği Bölümü, Konya Teknik Üniversitesi, Konya, Türkiye

2İletişim: saban.ozturk@amasya.edu.tr (https://orcid.org/ 0000-0003-2371-8173)

Elektrik Elektronik Mühendisliği Bölümü, Amasya Üniversitesi, Amasya, Türkiye
} 


\title{
Roof-CNN: Convolutional Neural Network Model with Less Parameters for Semantic Segmentation of Buildings
}

\begin{abstract}
Today, solar energy has become an indispensable element in providing energy infrastructure. Estimating the solar energy potential of building roofs in residential areas is important for the effective use of this energy. Nowadays, thanks to the developments in artificial intelligence algorithms, these tasks are performed automatically by computers. In this study, a solution is proposed by using deep learning architectures, which are the most advanced artificial intelligence algorithms. Convolutional Neural Network model called Roof-KSA with less parameters was proposed for semantic segmentation of building roofs in this research. A total of 3400 satellite images in $224 \times 224 \times 3$ pixels size were used for semantic segmentation. Roof-CNN model has a total of 10 layers and 104,450 updated parameters. Within the scope of comparative analysis, Roof-CNN model has less parameters compared to U-Net models. In addition, Roof-KSA model stands out with 0.91404 global accuracy, 0.73092 mean accuracy, 0.65537 mean intersection over union, 0.84918 weighted intersection over union and 0.67244 mean BF score. As a result, it is seen that Roof-CNN model is more successful in accordance with obtained semantic segmentation results.
\end{abstract}

Keywords- Solar Energy, Deep Learning, Semantic Segmentation, Convolutional Neural Networks. 


\section{I.GİRIŞ}

İnsan ihtiyaçlarının giderilmesinde enerjinin rolü oldukça büyüktür. Özellikle tarım, sanayi, ulaşım, tekstil ve hatta gıda gibi birçok alanda elektrik enerjisine ihtiyaç vardır [1]. Enerjinin kesintisiz olarak devam etmesi, üretimden hastanedeki cihazların düzenli çalışarak insan sağlığına etkisine kadar birçok alan için elzemdir. $\mathrm{Bu}$ yüzden elektrik enerjisinin üretimi süreklilik arz etmelidir. Kömür gibi fosil yakıtlar elektrik enerjisi üretmek için uzun yıllardan beri kullanılmaktadır [2]. Fakat fosil yakıtlar kullanılarak enerji üretimi sera gazı emisyonlarına neden olarak küresel ısınma gibi küresel problemlerin oluşmasını tetiklemektedir. Bu durum bir ikilemi doğurmaktadır; insan yaşamı için gerekli olan enerjiyi fosil yakıtlar kullanarak üretmek insan yaşamının sürekliliğini tehdit eden küresel ısınmaya neden olmaktadır. Bu problemin ortadan kaldırılması için güneş, rüzgâr, biokütle gibi temiz enerji kaynaklarının kullanılması önerilmiştir [3]. Bu kaynaklar dışarıdan hiçbir müdahaleye gerek duymadan sürekli olarak yenilendikleri için yenilenebilir enerji kaynakları ismini almışlardır. $\mathrm{Bu}$ kaynaklardan enerji üretimi sırasında doğaya verilen zarar minimum seviyede olduğu için bu kaynakların kullanımında son dönemlerde oldukça büyük bir artış vardır. Avrupa kıtasındaki açık deniz rüzgâr türbinleri kurulu gücü 2017 yılında 3.1GW'tır. 2016 yılının neredeyse iki katına eşit olan bu değer, ilerleyen yıllarda katlanarak artmaktadır [4]. Yenilenebilir enerji kaynaklarının kullanımının artması oldukça umut vericidir. Bunun yanı sıra araştırmacılar hangi yenilenebilir enerji kaynağının daha verimli olduğu konusunda bir takım çalışmalar yürütmüşlerdir. Sadece enerji üretmekle kalmayıp bunun yanında su 1sıtma sistemi olarak kullanılması, birçok ülkede yemek pişirme sistemlerine dönüştürülmesi ve mekân 1sıtıcısı olarak kullanılması sebebiyle güneş enerjisi oldukça öne çıkmaktadır. Bunlara ek olarak, rüzgâr enerjisi, jeotermal enerji, hidroelektrik gibi sistemlerden üretilen enerjinin uzak bölgelere ulaştırılması için harcanan ekonomik parametreler güneş enerjisinde gerekmemektedir [5]. Bu açıdan bakıldığında oldukça ekonomiktir. Bununla birlikte, her geçen yıl güneş paneli kurulum maliyetlerinin azaldığı gözlemlenmektedir.

Sürdürülebilir bir kalkınma ve sağlıklı bir dünya için fosil yakıtlardan elde edilen toplam enerji miktarının azaltılması oldukça önemlidir. Bu amaçla bireysel bazda alınabilecek en verimli önlem güneş panelleri kullanarak kendi enerjimizi bir ölçüde üretebilmektedir. Güneş enerjisini elektrik enerjine dönüştürmek için fotovoltaik (PV) paneller kullanılmaktadır [6]. Kelime anlamı olarak fotondan elektrik üretimi anlamına gelen fotovoltaik terimi aslında uzun yıllardan beri kullanılmaktadır. Fotovoltaik panellerin gelişim ve yayılım eğilimine baktığımızda teknolojinin gelişmesiyle çatılarımıza kadar gelmiştir. Özellikle dünyada üretilen enerjinin \%20.1'inin evlerde tüketildiği düşünüldüğünde her evin çatısında elektrik üretiminin gerekliliği ortaya çıkmaktadır [7]. 2040 yılına geldiğimizde ise bu oranın \%14 artacă̆ı öngörülmektedir [8].

Günümüzde birçok evin çatısı incelendiğinde düz veya belirli bir eğimde olduğu ortaya çıkmaktadır. Düz veya az eğimli yüzeylerin güneş panelleri için uygun olduğu bilinmektedir. Bina çatılarının bu yapıları bol güneş alan bölgelerde oldukça kullanışlıdır. Bu binaların çatılarına güneş panellerinin kurulması hem elektrik enerjisi üretilmesini hem de sıcak su ihtiyacını karşılayacaktır. Burada en önemli konulardan bir tanesi çatıların güneşe maruz kalma süresinin hesaplanması ve verimin belirlenmesidir. Bazı durumlarda yüksek binalardan ve çeşitli faktörlerden dolayı her evin çatısına yeterli miktarda güneş gelmeyebilir. Bu durumlarda daha verimli yenilenebilir enerji yöntemlerinin seçilmesi gerekmektedir. Aksi halde PV sisteminin kurulum maliyetinin geri kazanılması çok uzun yıllar sürebilir [9]. Bu sebeple literatürde birçok araştırmacı güneşlenme süresi üzerine araştırmalar yapmıştır. Bu çalışmalar genellikle geniş bir bölgenin tamamı üzerine ortalama tahminlerden oluşmaktadır [10, 11]. Fakat böyle tahminler bazı küçük yerleşim birimleri için oldukça yanıltıcı olabilmektedir. Daha da önemlisi aynı bölge içerisinde bile bazı binalar hiç güneş almazken bazı binalar ise iyi güneş alabilirler. Bu sebeple oldukça dar bir alanda bu hesaplamaların yapılması ve hatta ideal olarak bina bazlı bu hesaplamaların yapılması gerekmektedir. Fakat bina bazlı hesaplamalar manuel olarak gerçekleştirilirse bu oldukça uzun zaman ve işgücü gerektirir. Bu zorluğun önüne geçebilmek için literatürde bilgisayar tabanlı sistemlerden ve yapay zekâdan yararlanılmaktadır [12]. Hava araçlarından veya uydudan alınan görüntüler kullanarak ve bina çatılarının durumları incelenerek güneş alma süreleri ve çatının uygunluk durumu gibi birçok bilgi otomatik olarak elde edilebilir. Görüntü işleme tekniklerinin ve görüntüleme cihazlarının gelişmesini sayesinde bu işlemi saniyeler içerisinden yapmak olasıdır. Özellikle günümüzde Konvolüsyonel Sinir Ağları (KSA) gibi görüntü işleme problemleri için özel geliştirilen ağlar yardımıyla işlem başarısı da oldukça yüksek olmaktadır [13]. KSA, görüntü işleme problemleri için özel olarak geliştirilmiş iki boyutlu filtrelerin görüntü üzerinde kaydırılması ile çalışan otomatik bir görüntü işleme tekniğidir. Görüntü sınıflandırma, bölütleme, iyileştirme, kayıt ve erişim gibi bütün görüntü problemlerinde kullanılabilir [14]. Giriş görüntüleri ve çıkış hedefleri ile yeterli seviyede eğitilen bir KSA 
mimarisi bir uzman gibi kararlar verebilmektedir. Bu sebeple bina çatılarında otomatik olarak güneş paneli verimi tespitinde kullanılabilecek en uygun teknik olarak düşünülmüştür.

$\mathrm{Bu}$ çalı̧̧mada bina çatılarının güneş enerjisi potansiyeli KSA mimarisi kullanılarak hesaplanmaktadır. Havadan çekilmiş uydu görüntüleri kullanılarak her binanın potansiyeli otomatik olarak değerlendirilmekte ve güneş paneli kurulup kurulamayacağı kararı verilmektedir. Bu amaçla ilk olarak uydudan alınmış görüntülerde, binalar ve diğer alanlar tespit edilmektedir. Bu işlem önerilen Roof-KSA mimarisi tarafından otomatik olarak orta katmanlarda gerçekleştirilmektedir. Roof-KSA giriş katmanlarında kenar ve renk gibi daha düşük seviye bilgileri öğrenirken, orta katmanlarda ise binalar ve diğer görüntü nesnelerinin birbirinden ayrılmasını öğrenir. Önerilen mimarinin ileriki katmanlarında ise daha zorlayıcı bir görev olan hangi piksellerin çatı ile alakalı olduğu hangi piksellerinde binanın diğer bölümleriyle ilgili olduğu bilgiler otomatik olarak tespit edilmektedir. Önerilen yöntemin diğer yöntemlere göre en büyük avantajı ve literatüre katkısı çatı bulmak için özel olarak geliştirilmesi sayesinde küçük çatıları yüksek duyarlılıkla yakalayabilmesidir. Buna ek olarak, konvolüsyon kernelleri ile işlem yapıldığından her bir binanın tespiti için özel olarak işlem yaparken aslında eş zamanlı olarak tüm görüntüyü de tarar.

Çalışmanın geri kalanı şu şekildedir; kullanılan veri kümesi ve yöntemin detayları Bölüm 2'de anlatılmaktadır. Bölüm 3’te elde edilen bulgular ve tartışma sunulmaktadır. Bölüm 4'te sonuçlar yer almaktadır.

\section{MATERYAL VE YÖNTEM}

\section{A. Veri Kümesi}

Önerilen yöntemin test edilmesi amacıyla Massachusetts Building Dataset [15] ismi verilen veri kümesi kullanılmaktadır. Veri kümesi iki adet görüntü tipi içermektedir. İlk görüntüler orijinal görüntüler olarak adlandırılan üç kanallı uydu görüntüleridir. İkinci sınıftaki görüntüler ise tek kanaldan oluşmaktadır ve orijinal görüntülerin hedef görüntüleridir. Yani Şekil 1'de görüldüğü gibi çatıların açıkça işaretlendiği görüntülerdir. Toplamda 150 adet görüntüden oluşan bu veri kümesindeki her görüntünün çözünürlüğü 1500×1500 pikseldir. Veri kümesi kendi içerisinde eğitim, doğrulama ve test olmak üzere üç bölüme ayrılmıştır. Deneylerimiz sırasında bu görüntülerden $224 \times 224$ piksel boyutlarına sahip bölümler alınmıştır. Bu bölümler toplamda 3400 adet görüntüden oluşmaktadır. Görüntülerin 2400 adeti eğitim, 200 adeti doğrulama ve 800 adeti de test verisi için ayrılmıştır. Bu işlemin uygulanmasının temel nedeni donanımsal kapasitesinin kısıtlı olasıdır. Şekil 1'de oluşturulan veri seti kümesinden orijinal görüntü ve hedef görüntüler bulunmaktadır.

\section{B. Derin Öğrenme ve Konvolüsyonel Sinir Ağları}

Yapay zeka insan beynini öğrenme sisteminden yararlanarak geliştirilmiş bir makine öğrenmesi tekniğidir. İnsan beyni sinir sistemi içerisinde gerçekleşen öğrenme faaliyetlerine benzer olarak nöron modelleri geliştirilerek çeşitli mantıksal işlemlerin gerçekleştirilmesini sağlamaktadır [16]. İlk zamanlarda sadece basit ve tekrarlayan işlemlerin yapılması için düşünülen yapay zekâ algoritmaları günümüzde oldukça karmaşık görevleri yerine getirebilmektedir. Hatta insan sağlığı için tehlikeli görevlerin yerine getirilmesi veya insan kabiliyetlerinin yetersiz kaldığı durumlarda yapay zekâdan faydalanılmaktadır [17]. Yapay sinir ağları ile başlayan bu macera günümüzde teknolojinin oldukça gelişmesi ile tam otomatik sistemlere kadar ilerlemiştir. Dahası yapay zekânın insan ırkına üstünlük kurabileceğine dair tartışmalar bile başlamıştır [18]. Günümüz yapay zeka teknikleri birçok görevi defalarca tekrarlayarak öğrenmekte ve benzer görevleri kusursuzca yerine getirebilmektedir. Bu çalışmada ise görüntü işleme üzerine son yılların en önemli yapay zeka mimarisi kabul edilen KSA üzerinde durulacaktır. Aslında fikirsel temelleri 1989 yllına dayanan bu mimari 2011'de bir görüntü işleme yarışmasının kazanılmasından sonra ünlü hale gelmiştir [19]. Bunca yıl beklemesinin diğer sebebi ise donanımsal eksikliktir.

KSA mimarisi; konvolüsyon, havuzlama, lineer birim (ReLU), gizli katmanlar, sinıflama katmanı, kaçınma katmanı gibi birçok katmanın bir araya gelmesinden oluşmaktadır. Saydıklarımız neredeyse tüm KSA mimarilerinde bulunan temel katmanlar olarak görülse de bazı katmanlar kullanılmayabilir veya bazı farklı katmanlar eklenebilir. Çünkü günümüzde KSA mimarileri ile oldukça yoğun çalışmalar gerçekleştirilmektedir ve neredeyse her gün yeni bir mimari veya yeni bir katman önerilmektedir [20]. KSA mimarisinin görüntü işleme problemlerindeki başarısının anlaşılması için katmanlarının incelenmesi gerekmektedir. $\mathrm{Bu}$ amaçla temel katmanlar sırayla açıklanacaktır. Fakat öncelikle KSA mimarisi sadece bir konvolüsyon, bir havuzlama ve ReLU 
katmanından oluşması durumunda çıkışında elde edilecek değer anlatımın basit olması için açıklanacaktır. Eşitlik 1 tek katmanlı bir KSA çıkışını hesaplamak için kullanılmakladır.

$$
f(I)=\operatorname{pool}_{n x n}(\sigma(w \times I+b))
$$

Eşitlik 1'de $I$ giriş görüntüsünü, pool havuzlama işlemini, $n$ havuzlama matrisinin boyutunu, $\sigma$ aktivasyon fonksiyonunu, $w$ konvolüsyon katmanındaki ağırlıkları, $x$ konvolüsyon işlemini ve $b$ konvolüsyon katmanı bias değerini temsil etmektedir. Konvolüsyon katmanı kernel ismi verilen özellik matrislerinden oluşmaktadır. Bu özellik matrisleri görüntüden daha küçük boyutlardadır ve görüntü üzerinde kaydırılmaktadır. Ağın öğrendiği özellikler bu matrisler içerisinde saklanmaktadır. Bir konvolüsyon katmanında birden fazla özellik matrisi bulunmaktadır ve konvolüsyon matrislerindeki tüm değerler eğitilebilirdir. Eğitim sırasında bu değerler güncellenerek ağın özellikleri öğrenmesi sağlanmaktadır. Bu katmandaki özellik matrislerinin görüntü üzerinde kaydırılması sayesinde parametre sayısı oldukça azalmaktadır. Buna literatürde özelliklerin paylaşımı ismi verilmektedir. 


\begin{tabular}{|c|c|c|}
\hline & $\begin{array}{l}\text { BŞEÜ Fen Bilimleri Dergisi } \\
7(2), 1094-1105,2020\end{array}$ & $\begin{array}{r}\text { BSEU Journal of Science } \\
\text { DOI: } 10.35193 / \text { bseufbd.741729 }\end{array}$ \\
\hline $\begin{array}{l}\text { SEYHE } \\
\text { ERR I }\end{array}$ & & 58-7575 (http://dergipark.gov.tr/bseufbd) \\
\hline
\end{tabular}
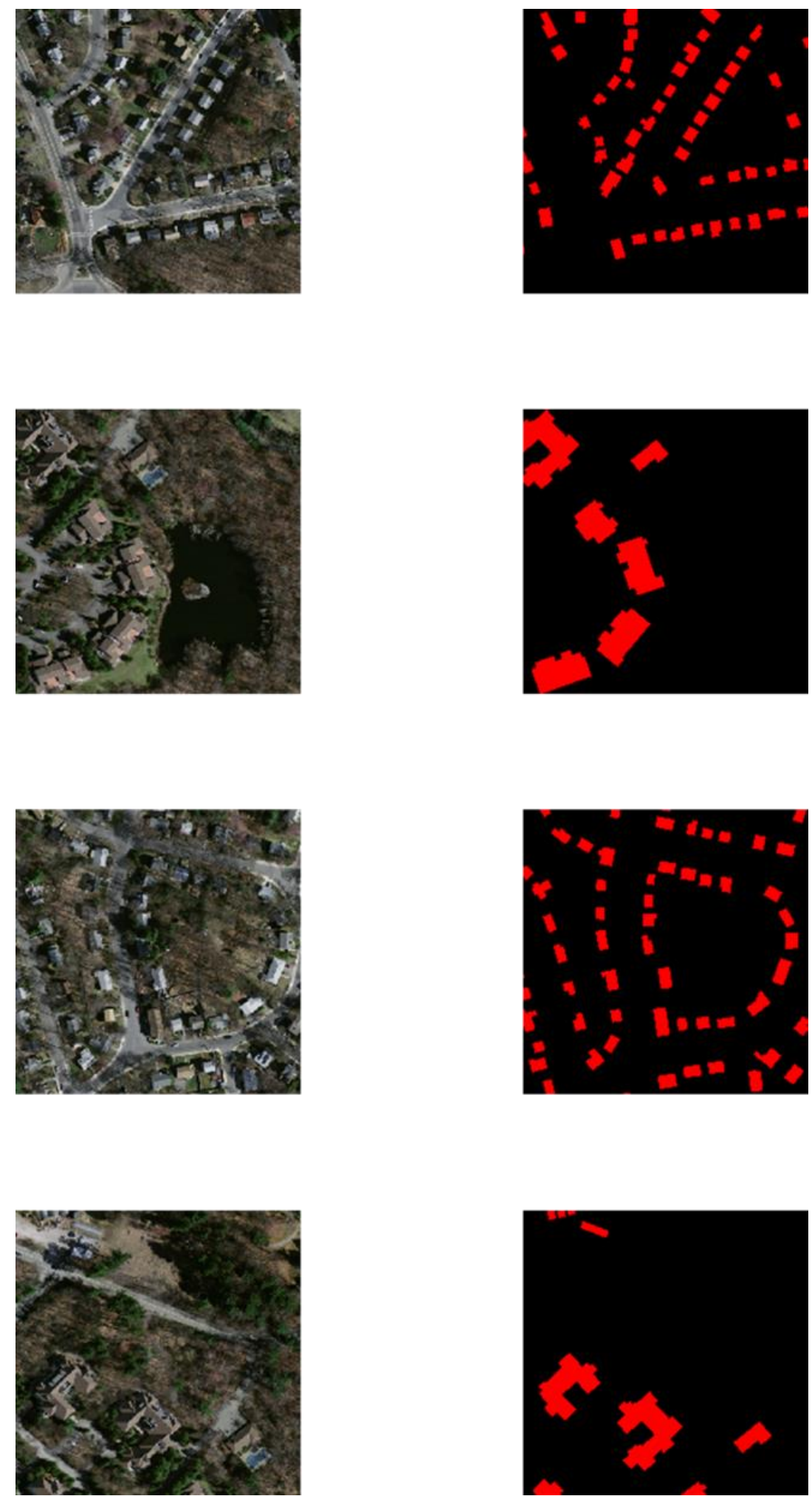

Şekil 1. Orijinal görüntü (solda), hedef görüntü (sağda) 
Havuzlama katmanının görevi ise en basit tanımıyla matristeki önemli özellikleri koruyarak matris boyutunu düşürmektedir. Böylece eğitilmesi gereken parametre sayısı azaltılarak donanımsal yeterlilik desteklenmektedir. Buna ek olarak eğitim süresinin kısalması ve ezberleme eğiliminin azalması gibi katkıları da göz ardı edilemez. Problemin durumuna göre havuzlama yöntemi seçilebilir. Literatürde en sık karșılaşılan havuzlama teknikleri; maksimum havuzlama, ortalama havuzlama ve toplam havuzlamadır. Bu yöntemlerde öncelikle bir pencere boyutu belirlenmektedir ve bu pencere kare olmalıdır. Görüntü üzerinde kaydırılan bu pencerenin altında kalan pikseller ile ilgili işlemler yapılır. Maksimum havuzlama için pencere altında kalan piksellerden en büyük değerli piksel seçilerek işlemlere sadece o pikselle devam edilir. Ortalama havuzlama için pencere altındaki piksellerin ortalaması alınır, toplam havuzlamada ise pencere altında kalan piksellerin toplam değeri ile işlemlere devam edilir. Bu işlemin en önemli avantajı bilgi kaybı olmadan matris boyutunun önemli ölçüde küçülttülmesidir.

Düzeltilmiş Doğrusal Birim (ReLU) katmanı ağın doğrusallığını bozmak için kullanılan bir aktivasyon fonksiyonudur. Bu katman sayesinde özellikle derin ağların en büyük problemlerinden biri olan ağdaki eğitim örneklerine aşırı uyum probleminin önüne geçilebilmektedir. Buna ek olarak gradyan değerinin yok olmasını önleyerek güncelleme işleminin sıfir değerine dönüşmesini önleyebildiği durumlarda mevcuttur.

Tam bağlı katmanı (FCL) matris halinde devam eden KSA mimarisinin artık vektör haline gelmesini sağlamaktadır. $\mathrm{Bu}$ kısımda matris haline dönüştürülen özellikler geleneksel yapay sinir modeli ile sınıflandırılmaktadır. İstenilen sınıf sayısı ve gizli katman özelliklerine göre ağın bu kısmı aynı diğer kısımları gibi değiştirilebilir. Sınıflama işlemlerinde kullanılan ve sınıflama katmanı olarak ta adlandırılabilen softmax katmanı çoklu sınıflarda olasııık dağılımına göre sınıf oranları belirlemektedir. Genellikle ağın son katmanı olarak kullanılır.

Temel katmanlar arasında olmamalarına rağmen neredeyse her mimaride karşımıza çıkan bir diğer katman ise kaçınma (dropout) katmanıdır. Ne kadar önlem alınırsa alınsın derin ağlar her zaman eğitim verilerini ezberleme eğilimindedir. Ağın bir önceki katmanlarında bu işlemin önlenmesine destek olan katmanlardan bahsettik. Fakat son durumda ağ parametreleri öğrenme işlemini işbirlikçi olarak yapmaktadır. Yani birbirinin oranlarına göre güncelleme yapmaktadır. Bu durumda eğitim işlemi istenen başarıya ulaşamaz. Bu durumu kırmak için kaçınma katmanı kullanılır. Kaçınma katmanı eğitim aşamasında belirlenen değere göre ağın belli bir yüzdesinin kullanılmasını sağlayarak nöronlar arası güncellemeyi kontrol eder. Son olarak birleştirme katmanı ise iki farklı matrisi arka arkaya ekleyerek birleştir [21].

\section{C. Önerilen KSA Mimarisi}

Derin mimariler oldukça kapsamlı olması sayesinde öğrenme işlemi oldukça kuvvetli ve gürbüz biçimde yerine getirirler. Fakat çok fazla eğitilebilir parametre olması eğitim için gerekli olan örnek ihtiyacını artırır. Buna ek olarak ağın ezberlemeye olan kırılganlığını artıır. Önerilen yöntemde az parametre kullanılarak yüksek bir bölütleme performansı elde etmek amaçlamıştır. Tasarlanan KSA ağı toplamda 10 katmandan oluşmaktadır. KSA ağının ilk katmanı görüntü giriş katmanı olup $224 \times 224 \times 3$ piksel boyutundadır. Buradadik $224 \times 224$ giriş görüntüsünün boyutlarını belirtmektedir. 3 rakamı ise giriş görüntüsü renkli olduğunda kullanılır. Sonrasında sırasıyla birer adet konvolüsyon ve ReLU katmanı bulunmaktadır. Konvolüsyon katmanı 64 adet $3 \times 3$ görüntü filtrelerinden oluşmaktadır. Konvolüsyon katmanında kayma adımı 1 olup 1 piksel genişliğinde dolgu işlemi uygulanmıştır. Ardından maksimum havuzlama, konvolüsyon ve ReLU katmanları gelmektedir. Maksimum havuzlama katmanında $2 \times 2$ havuzlama pencereleri bulunmaktadır. Havuzlama katmanında dolgu işlemi uygulanmamış olup kayma adımı 2 olarak belirlenmiş̧tir. Sonrasında gelen konvolüsyon katmanında 64 adet $3 \times 3$ görüntü filtreleri mevcut olup kayma adımı 1 olacak şekilde tasarlanmıştır. Bu katmanda herhangi bir dolgu işlemi uygulanmamıştır. Her konvolüsyon katmanından soran ise ReLU aktivasyon fonksiyonu tercih edilmiştir. ReLU aktivasyon fonksiyonu kullanılarak Roof-KSA mimarisindeki doğrusallık giderilmeye çalışılmışıtır. Son dört katman sırasıyla transpose konvolüsyon katmanı, konvolüsyon katmanı, softmax ve çıkış katmanıdır. Transpose konvolüsyon katmanı öğrenilebilir parametrelere sahip olup hedef görüntünün elde edilmesi için önemli bir katmandır. Transpose konvolüsyon katmanı normal konvolüsyon katmanın tam tersi olarak işlem yapmaktadır. $\mathrm{Bu}$ katman görüntü boyutlarını tekrardan büyütmeye başlar. Roof-KSA yapısında transpose konvolüsyon katmanı içerisinde 64 adet $4 \times 4$ görüntü filtreleri bulunur. Kayma adımı ise 2 birimdir. Sonrasında bulunan konvolüsyon katmanında 2 adet $1 \times 1$ filtre boyutuna sahip konvolüsyon filtresi bulunur. Kayma adımı 1 olarak belirlenmiştir. 
Son iki katman ise piksel sınıflaması için softmax ve çıkıs katmanı bulunmaktadır. Şekil 2'de Roof-KSA mimarisinin yapısı bulunmaktadır. Aynı zamanda Tablo 1'de katmanlara ait parametre sayıları bulunmaktadır.

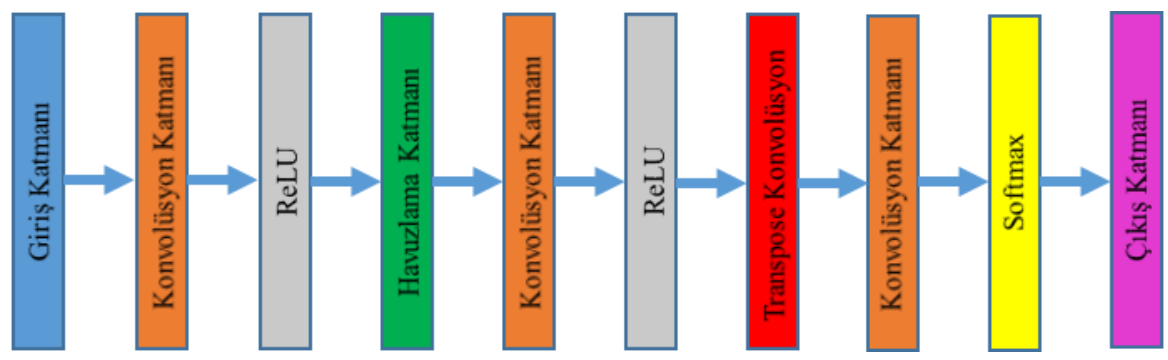

Şekil 2. Önerilen Roof-KSA Yapısı

Bu çalışmadaki Roof-KSA mimarisinin eğitimi sırasında eğitim oranı 0.0001 olarak kullanılmaktadır. Eğitim işleminde görüntüler küçük gruplara ayrılmaktadır. Bu küçük gruplar 16 adet görüntülerden oluşmaktadırlar. Parametrelerin güncellenmesi için ise stokastik gradyant azalma algoritması kullanılmaktadır.

Tablo 1. Önerilen Roof-KSA Yapısının Parametre Değerlendirilmesi

\begin{tabular}{ccc}
\hline Katmanlar & Öğrenilen Parametreler & Parametre Sayısı \\
\hline Giriş Katmanı & - & - \\
Konvolüsyon Katmanı & $3 \times 3 \times 3 \times 64$ & 1792 \\
ReLU & $1 \times 1 \times 64$ & - \\
Maksimum Havuzlama & - & 36928 \\
Konvolüsyon Katmanı & - & - \\
ReLU & $3 \times 3 \times 64 \times 64$ & 65600 \\
Transpose Konvolüsyon & $1 \times 1 \times 64$ & 130 \\
Konvolüsyon Katmanı & - & - \\
Softmax & $4 \times 4 \times 64 \times 64$ & - \\
Çıııs Katmanı & $1 \times 1 \times 64$ &
\end{tabular}

\section{BULGULAR VE TARTIȘMA}

Çalışma kapsamında uydu görüntüleri içerisindeki çatıların bölütlenmesi sağlanarak ilgilenilen bölgenin günȩ̧ enerjisi üretim kapasitesinin anlaşılması amaçlanmıştır. Toplamda 3400 adet $224 \times 224 \times 3$ piksel boyutlarında uydu görüntüsü kullanılmıştır. Bu görüntülerin hepsi renkli görüntülerdir. Verilerin 2400 adeti eğitim, 200 adeti doğrulama ve 800 adeti test işlemi için ayrılmıştır. Bulguların elde edilmesi sürecinde $3.3 \mathrm{GHz}$ 'lik Intel Core i7 işlemci gücüne sahip bilgisayar ve NVIDIA GTX 1050 TI ekran kartından yararlanılmıştır. Eğitim aşamasında Roof-KSA mimarisi için bazı eğitim ayarları gerçekleş̧irilmiş̧ir. Toplam epok sayısı 25 olarak belirlenmiş ve öğrenme oranı $10^{-4}$ olarak seçilmiştir. Optimizasyon yöntemi olarak Stokastik Gradyan Azalış algoritması kullanılmıştır. Analizlerin tamamı Matlab 2019b programı kullanılarak gerçekleștirilmiştir. Ayrıca karşılaştırmalı analiz kapsamında 3 ve 5 derinlikli U-Net mimarilerinin metrik sonuçları karşılaştııılmıştır. Elde edilen metrik sonuçları Tablo 2'de yer almaktadır. 


\begin{tabular}{|c|c|c|}
\hline & $\begin{array}{l}\text { BŞEÜ Fen Bilimleri Dergisi } \\
7(2), 1094-1105,2020\end{array}$ & $\begin{array}{r}\text { BSEU Journal of Science } \\
\text { DOI: } 10.35193 / \text { bseufbd.741729 }\end{array}$ \\
\hline $\begin{array}{l}\text { BiLECIK SEYY EDEBAL } \\
\text { ONIVERSITESI }\end{array}$ & & 58-7575 (http://dergipark.gov.tr/bseufbd) \\
\hline
\end{tabular}

Tablo 2. Karşıllaştırmalı Analiz Sonuçları

\begin{tabular}{cccccc}
\hline Yöntemler & $\begin{array}{c}\text { Küresel } \\
\text { Doğruluk }\end{array}$ & $\begin{array}{c}\text { Ortalama } \\
\text { Doğruluk }\end{array}$ & $\begin{array}{c}\text { Ortalama } \\
\text { EBO }\end{array}$ & $\begin{array}{c}\text { Ağırlıklandırılmıs } \\
\text { EBO }\end{array}$ & $\begin{array}{c}\text { Ortalama BF } \\
\text { Skoru }\end{array}$ \\
\hline U-Net-3 & 0.90253 & 0.64095 & 0.582 & 0.82445 & 0.62139 \\
U-Net-5 & 0.89724 & $\mathbf{0 . 7 4 9 8 1}$ & 0.63964 & 0.83116 & 0.62417 \\
Roof-KSA & $\mathbf{0 . 9 1 4 0 4}$ & 0.73092 & $\mathbf{0 . 6 5 5 3 7}$ & $\mathbf{0 . 8 4 9 1 8}$ & $\mathbf{0 . 6 7 2 4 4}$ \\
\hline
\end{tabular}

Tablo 2 incelendiğinde önerilen yöntemin metrik performansı 3 ve 5 derinlikli U-Net yapılarının performansından daha yüksek olduğu görülmektedir. Küresel doğruluk metriğinde Roof-KSA yapısı 0.91404 değerine sahiptir. En düşük performansı 0.89724 değeri ile U-Net-5 modeli sahiptir. Ortalama doğruluk değerleri dikkate alındığında U-Net-5 modeli 0.74981 metrik değerine sahiptir. Ortalama Eşleşmiş Bölge Oranı (Ortalama EBO) metriğinde Roof-KSA yapısı 0.65537 değeri ile en yüksek performansı elde etmiştir. En yüksek Ağırlıklandırılmış EBO ve ortalama BF skoru metrik değerleri 0.84918 ve 0.67244 ile Roof-KSA yapısına aittir. Tablo 3'de U-Net yapıları ve Roof-KSA yapısının toplam katman sayısı ve toplam güncellenen parametre sayıları verilmiştir.

Tablo 3. Modelleri Karşılaştırmalı Toplam Katman ve Parametre Sayıları

\begin{tabular}{ccc}
\hline Yöntemler & $\begin{array}{c}\text { Toplam } \\
\text { Katman } \\
\text { Sayısı }\end{array}$ & $\begin{array}{c}\text { Öğrenilen } \\
\text { Parametreler }\end{array}$ \\
\hline U-Net-3 & 46 & $7,697,410$ \\
U-Net-5 & 70 & $124,362,242$ \\
Roof-KSA & $\mathbf{1 0}$ & $\mathbf{1 0 4 , 4 5 0}$ \\
\hline
\end{tabular}

Toplam parametre sayıları dikkate alındığında önerilen Roof-KSA 104,450 adet güncellenen parametre sayısı ile eğitimi ve test süreleri en düşük modeldir. U-Net-5 ve U-Net-3 modelleri 7,697,410 ve 124,362,242 adet toplam güncellenen parametre sayısı ile oldukça ağır modellerdir. Toplam katman sayısı incelendiğinde 10 adet katman sayısı ile en az katmana sahip model Roof-KSA'dir. U-Net-5 modeli 70 adet katman ile en fazla katmana sahip KSA modelidir. Şekil 3'de karşılaştırmalı olarak elde edilen bölütlenmiş görüntüler yer almaktadır.

Önerilen yöntemin sonuçları literatürde sıklıkla kullanılan ve oldukça güçlü olan mimarilerden daha dikkat çekicidir. Bunun yanında önerilen yöntemin hızı U-Net-3 ve U-Net-5 mimarilerinden oldukça hızlıdır. Test aşamasında diğer mimarilere nazaran neredeyse 10 kat daha çabuk bir biçimde sonuç üretmektedir. Bu hızın sebebi Roof-KSA parametre sayısının diğer mimarilere göre oldukça az olmasıdır. Yüksek performans göstermesindeki en önemli etken ise veri kümesine göre yapılmış olan tasarımdır. Bu çalışmada kullanılan verilerin sayısı büyük mimarilerin eğitimi için yeterli gelmemektedir. Bu sebeple önerilen Roof-KSA mimarisi hem performansı hem de hızı bakımından en verimli yöntemdir. 


\begin{tabular}{|c|c|c|}
\hline & $\begin{array}{l}\text { BŞEÜ Fen Bilimleri Dergisi } \\
\text { 7(2), 1094-1105, } 2020\end{array}$ & $\begin{array}{r}\text { BSEU Journal of Science } \\
\text { DOI: } 10.35193 / \text { bseufbd. } 741729\end{array}$ \\
\hline $\begin{array}{l}\text { BUECLSERHEDEAL } \\
\text { UNIVERSITESI }\end{array}$ & & 58-7575 (http://dergipark.gov.tr/bseufbd) \\
\hline
\end{tabular}
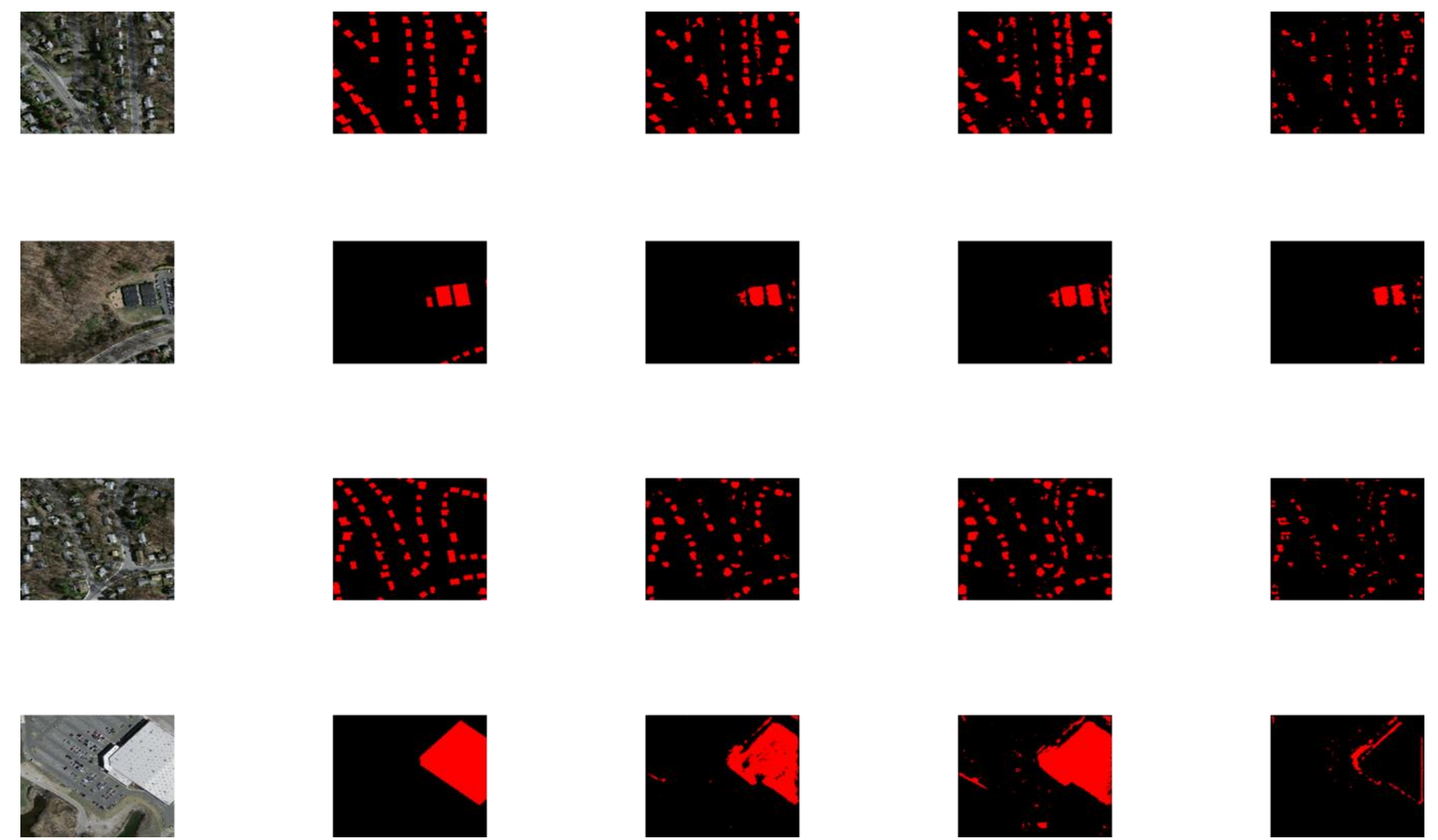

(a)

(b)

(c)

(d)

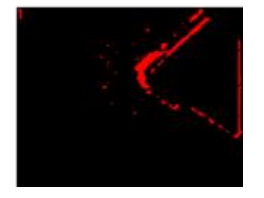

(e)

Şekil 3. a) Giriş Görüntüsü b) Maske Görüntüsü c) Roof-KSA İle Elde Edilen Sonuç d) U-Net-5 İle Elde Edilen Sonuç e) U-Net-3 İle Elde Edilen Sonuç 
Şekil 3'de verilen bölütleme sonuçları verilmiştir. Önerilen Roof-KSA ile elde edilen bölütleme sonuçları diğer yöntemlere nazaran oldukça başarılıdır. Görüntülerde tekli veya çoklu yerleşim yerlerinin bulunması RoofKSA yapısının bölütleme performansında herhangi bir etkisi olmadığı görülmektedir. U-Net-3 modelinde elde edilen performans düşüklüğü hem Şekil 3-e hem de Tablo 2'de verilen metrik performansında net bir şekilde görülmektedir.

\section{SONUÇLAR}

Bu çalışma uydudan alınmış görüntülerde çatıları bölütleyerek evlerin güneş enerjisi için uygunluğunu otomatik olarak ölçebilen bir yöntem sunmaktadır. Önerilen yöntem çatıların hızlı bir biçimde ve doğru olarak tespit edebilen bir KSA mimarisidir. Hızın korunması için daha az eğitilebilir parametreye sahip olan bu mimari Massachusetts Building Dataset veri seti kullanılarak eğitilmiştir. Önerilen yöntemin başarısının karşılaştırılması için literatürdeki en başarılı segmentasyon yöntemlerinden olan u-net mimarisi kullanılmıştır. Birbirine eş olarak yapılan deneyler önerilen yöntemin diğer yöntemlerden daha yüksek başarıya sahip olduğunu göstermektedir. Buna ek olarak önerilen yöntem diğer yöntemlerden neredeyse 10 kat daha hızlı biçimde sonuç üretmektedir. Bu sonuçlar göstermektedir ki verilere göre oluşturulan mimari verimliliği gelecekte algoritma oluşturmayı büyük ölçüde etkileyecektir. Son olarak gelecekte yapılması planlanan çalışmalar için çatılar üzerinde güneş panelinin tespiti ve çatıların boyutlarının tespiti gerçekleştirilebilir.

\section{KAYNAKLAR}

[1] Harrouz, A., Colak, I., Kayisli, K. (2019). Energy Modeling Output of Wind System based on Wind Speed. In 2019 8th International Conference on Renewable Energy Research and Applications (ICRERA) (pp. 6368). IEEE.

[2] Rehman, A., Rauf, A., Ahmad, M., Chandio, A. A., Deyuan, Z. (2019). The effect of carbon dioxide emission and the consumption of electrical energy, fossil fuel energy, and renewable energy, on economic performance: evidence from Pakistan. Environmental Science and Pollution Research, 26(21), 21760-21773.

[3] Johlas, H., Witherby, S., Doyle, J. R. (2020). Storage requirements for high grid penetration of wind and solar power for the MISO region of North America: A case study. Renewable Energy, 146, 1315-1324.

[4] Robles, E., Haro-Larrode, M., Santos-Mugica, M., Etxegarai, A., Tedeschi, E. (2019). Comparative analysis of European grid codes relevant to offshore renewable energy installations. Renewable and Sustainable Energy Reviews, 102, 171-185.

[5] Akcan, E., Kuncan, M., Minaz, M. R. (2020). PVsyst Yazılımı İle 30 Kw Şebekeye Bağlı Fotovoltaik Sistemin Modellenmesi ve Simülasyonu. Avrupa Bilim ve Teknoloji Dergisi, (18), 248-261.

[6] Cui, Y., Yao, H., Zhang, J., Zhang, T., Wang, Y., Hong, L., Wei, Z. (2019). Over 16\% efficiency organic photovoltaic cells enabled by a chlorinated acceptor with increased open-circuit voltages. Nature communications, 10(1), 1-8.

[7] Khasraw Bani, R., Jalal, S. J. (2019). Impact of shadow distribution on optimizing insolation exposure of roofs according to harness or transfer of solar energy in Sulaimani city, Iraq. Renewable energy, 136, 452462.

[8] Eia, U. S. (2017). The international energy outlook 2016.

[9] Wu, G., Yang, Q., Fang, H., Zhang, Y., Zheng, H., Zhu, Z., Feng, C. (2019). Photothermal/day lighting performance analysis of a multifunctional solid compound parabolic concentrator for an active solar greenhouse roof. Solar Energy, 180, 92-103.

[10] Victoria, M., Andresen, G. B. (2019). Using validated reanalysis data to investigate the impact of the PV system configurations at high penetration levels in European countries. Progress in Photovoltaics: Research and Applications, 27(7), 576-592. 
[11] Ghimire, S., Deo, R. C., Downs, N. J., Raj, N. (2019). Global solar radiation prediction by ANN integrated with European Centre for medium range weather forecast fields in solar rich cities of Queensland Australia. Journal of cleaner production, 216, 288-310.

[12] Chen, C., Duan, S., Cai, T., Liu, B. (2011). Online 24-h solar power forecasting based on weather type classification using artificial neural network. Solar energy, 85(11), 2856-2870.

[13] Shen, S., Yang, H., Yao, X., Li, J., Xu, G., Sheng, M. (2020). Ship Type Classification by Convolutional Neural Networks with Auditory-Like Mechanisms. Sensors, 20(1), 253.

[14] Zhou, D. X. (2020). Universality of deep convolutional neural networks. Applied and computational harmonic analysis, 48(2), 787-794.

[15] Mnih, V. (2013). Machine learning for aerial image labeling. University of Toronto (Canada).

[16] Hassabis, D., Kumaran, D., Summerfield, C., Botvinick, M. (2017). Neuroscience-inspired artificial intelligence. Neuron, 95(2), 245-258.

[17] Nagy, G., Anderson, J. (2016, May). Active recruitment mechanisms for heterogeneous robot teams in dangerous environments. In Canadian Conference on Artificial Intelligence (pp. 276-281).

[18] Marr, B. (2018). Is Artificial Intelligence dangerous? 6 AI risks everyone should know about. Forbes.

[19] Krizhevsky, A., Sutskever, I., Hinton, G. E. (2012). Imagenet classification with deep convolutional neural networks. In Advances in neural information processing systems (pp. 1097-1105).

[20] Wei, Y., Xiao, H., Shi, H., Jie, Z., Feng, J., Huang, T. S. (2018). Revisiting dilated convolution: A simple approach for weakly-and semi-supervised semantic segmentation. In Proceedings of the IEEE Conference on Computer Vision and Pattern Recognition (pp. 7268-7277).

[21] Hu, W., Huang, Y., Wei, L., Zhang, F., Li, H. (2015). Deep convolutional neural networks for hyperspectral image classification. Journal of Sensors, 2015. 